\title{
Takotsubo Cardiomyopathy With Marked ST-Segment Elevation and Electrical Alternans Complicated With Hyperglycemic Hyperosmolar State
}

\author{
Kotaro OE, ${ }^{1} \mathrm{MD}$, Kiyoo MorI, ${ }^{2} \mathrm{MD}$, Michio OTsujI, ${ }^{2} \mathrm{MD}$, \\ Tetsuo Konno, ${ }^{3} \mathrm{MD}$, Noboru FuJINO, ${ }^{3} \mathrm{MD}$, and Masakazu YAMAGISHI, ${ }^{3} \mathrm{MD}$
}

\begin{abstract}
SUMMARY
This is the first report of a case of Takotsubo cardiomyopathy with a hyperglycemic hyperosmolar state (HHS). This case presented with marked ST-segment elevation and electrical alternans, uncommon findings in Takotsubo cardiomyopathy. We believe that hyperosmolarity-induced myocardial dehydration and consequent increase in intracellular calcium concentration may be the mechanism of Takotsubo cardiomyopathy and electrical alternans in HHS. (Int Heart J 2008; 49: 629-635)
\end{abstract}

Key words: Takotsubo cardiomyopathy, Electrical alternans, Hyperglycemic hyperosmolar state

THERE have been several reports of cardiac complications with a hyperglycemic hyperosmolar state (HHS), such as acute myocardial infarction ${ }^{1,2)}$ and heart failure. ${ }^{3)}$ However, there are no reports of Takotsubo cardiomyopathy with HHS. We report a case of Takotsubo cardiomyopathy with HHS exhibiting marked STsegment elevation and electrical alternans. The mechanism of these rare findings is discussed.

\section{CASE REPORT}

An 81-year-old woman was admitted to our hospital because of coma on September 2007. She had undergone clipping of a cerebral aneurysm due to subarachnoid hemorrhage at 53 years-old. She was diagnosed with diabetes mellitus at 61 years-old and had used insulin since she was 78. Before admission, she was febrile and could not eat for a few days. On admission, her blood pressure was 120/80 mmHg and her pulse rate was $110 \mathrm{bpm}$. Physical findings revealed dry tongue and decreased turgor of skin indicating dehydration. Chest $\mathrm{X}$-rays showed

From the ${ }^{1}$ Division of Internal Medicine, Saiseikai Kanazawa Hospital, ${ }^{2}$ Division of Internal Medicine, Houju Memorial Hospital, and ${ }^{3}$ Division of Cardiovascular Medicine, Kanazawa University Graduate School of Medicine, Ishikawa, Japan.

Address for correspondence: Kotaro Oe, MD, Division of Internal Medicine, Saiseikai Kanazawa Hospital, 13-6 Akatsuchimachi, Kanazawa, Ishikawa 920-0353, Japan.

Received for publication April 14, 2008.

Revised and accepted July 24, 2008. 
Table. Laboratory Data on Admission

\begin{tabular}{lc}
\hline Hematologic laboratory values & \\
White blood cell count $\left(/ \mathrm{mm}^{3}\right)$ & 16,000 \\
Red blood cell count $\left(/ \mathrm{mm}^{3}\right)$ & $372 \times 10^{4}$ \\
Hemoglobin $(\mathrm{g} / \mathrm{dL})$ & 12.1 \\
Hematocrit $(\%)$ & 36.7 \\
Platelet count $\left(/ \mathrm{mm}^{3}\right)$ & $8.7 \times 10^{4}$ \\
Blood chemical values & \\
Creatinine $(\mathrm{mg} / \mathrm{dL})$ & 0.7 \\
Urea nitrogen $(\mathrm{mg} / \mathrm{dL})$ & 59 \\
Na (mEq/L) & 186 \\
K (mEq/L) & 3.4 \\
Cl (mEq/L) & 143 \\
Total protein $(\mathrm{g} / \mathrm{dL})$ & 4.8 \\
Aspartate aminotransferase $(\mathrm{IU} / \mathrm{L})$ & 112 \\
Alanine aminotransferase $(\mathrm{IU} / \mathrm{L})$ & 55 \\
Lactate dehydrogenase $(\mathrm{IU} / \mathrm{L})$ & 552 \\
Creatine kinase $(\mathrm{IU} / \mathrm{L})$ & 679 \\
Glucose $(\mathrm{mg} / \mathrm{dL})$ & 421 \\
Hemoglobin A1C $(\%)$ & 8.2 \\
Osmolality (mosmol/L) & 423 \\
Arterial blood gas levels & \\
pH & 7.468 \\
Carbon dioxide tension $(\mathrm{mmHg})$ & 47.5 \\
Oxygen tension $(\mathrm{mmHg})$ & 88.1 \\
Bicarbonate $(\mathrm{mEq} / \mathrm{L})$ & 33.6 \\
& \\
\hline & \\
\hline
\end{tabular}

mild cardiomegaly and consolidation in the right upper lobe. A brain CT showed no cerebrovascular lesion. Laboratory data indicated marked hypernatremia (serum Na was $186 \mathrm{mEq} / \mathrm{L}$ ), hyperglycemia (plasma glucose was $421 \mathrm{mg} / \mathrm{dL}$ ), azotemia (serum urea was $59 \mathrm{mg} / \mathrm{dL}$ ), and hyperosmolality (serum osmolality was $423 \mathrm{mosmol} / \mathrm{L}$ ). Arterial blood gas sampling revealed no metabolic acidosis (Table). We made a diagnosis of pneumonia and a hyperglycemic hyperosmolar state, and saline infusion and insulin infusion were started. An electrocardiogram showed ST-segment elevation in leads V2, V3, and V4 and T wave inversion in leads I, II, III, aVF, and V1 6 (Figure 1). Echocardiography showed severe left ventricular dysfunction in the midventricle and apex with preserved basal function and no pericardial effusion. Left ventricular end-diastolic dimension was 45 $\mathrm{mm}$ and the left ventricular ejection fraction was $31 \%$ by the Simpson method. Mitral inflow velocity presented a restrictive filling pattern and the deceleration time was $121 \mathrm{~ms}$. Mild aortic regurgitation was present but mitral regurgitation was not. We suspected Takotsubo cardiomyopathy based on the echocardiogram findings, but acute myocardial infarction could not be excluded. Coronary angiography was not performed because we thought that contrast agent might be 

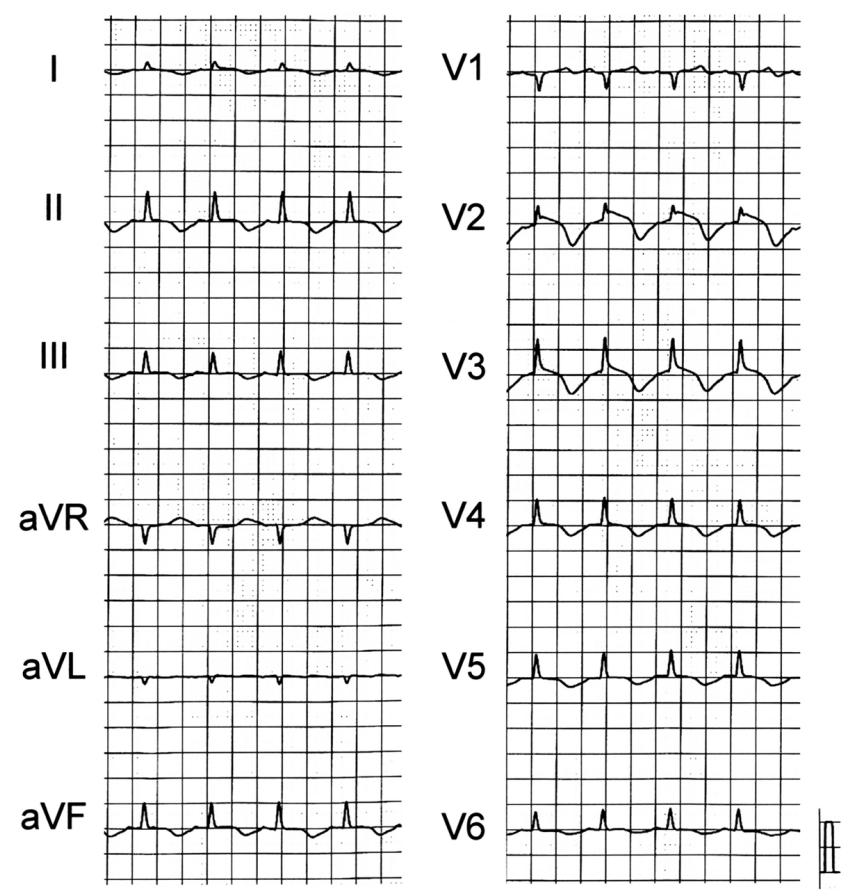

Figure 1. Electrocardiogram on admission.
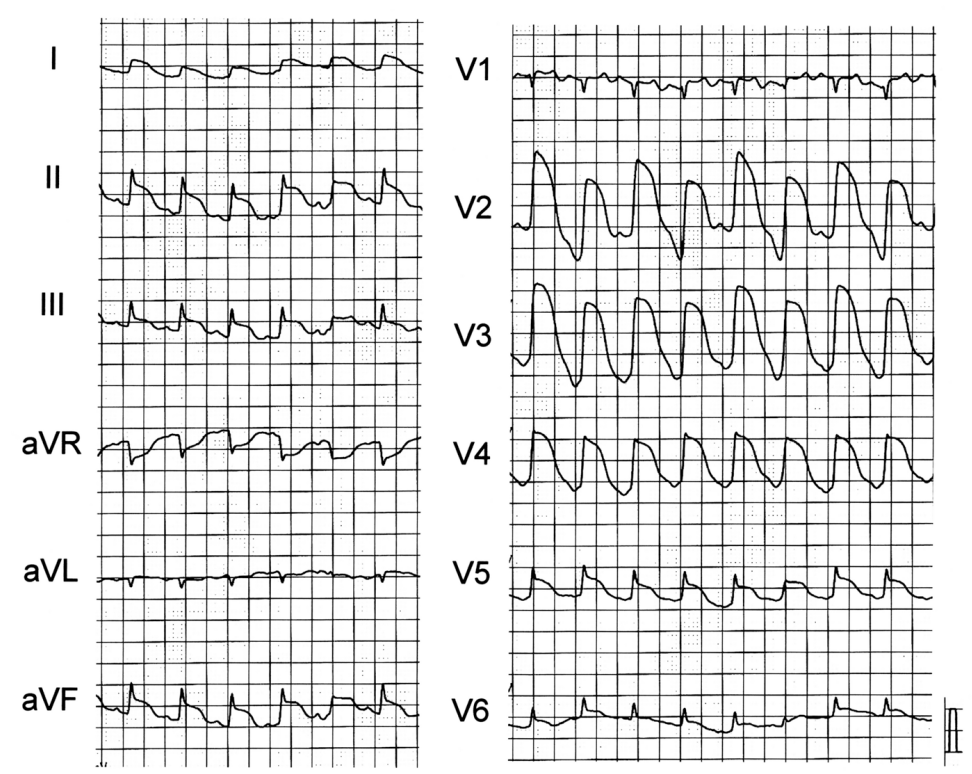

Figure 2. Electrocardiogram at 14 hours from admission. 


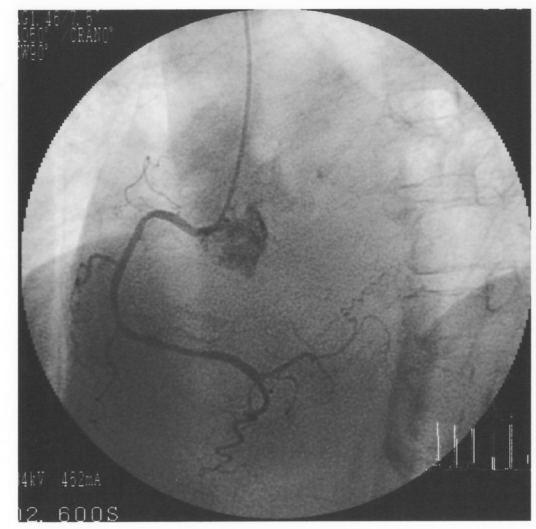

RCA

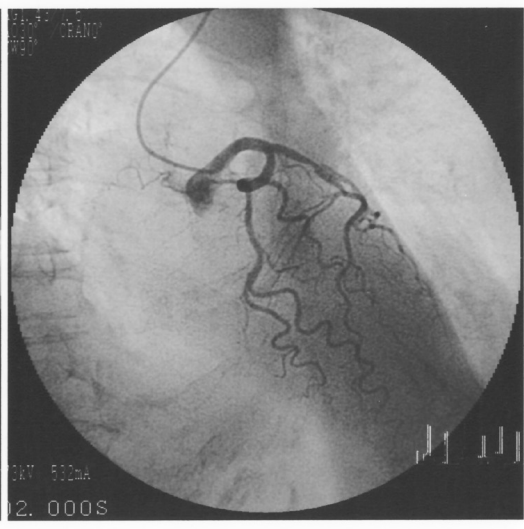

LCA

Figure 3. Coronary angiography. RCA indicates right coronary artery and LCA, left coronary artery.

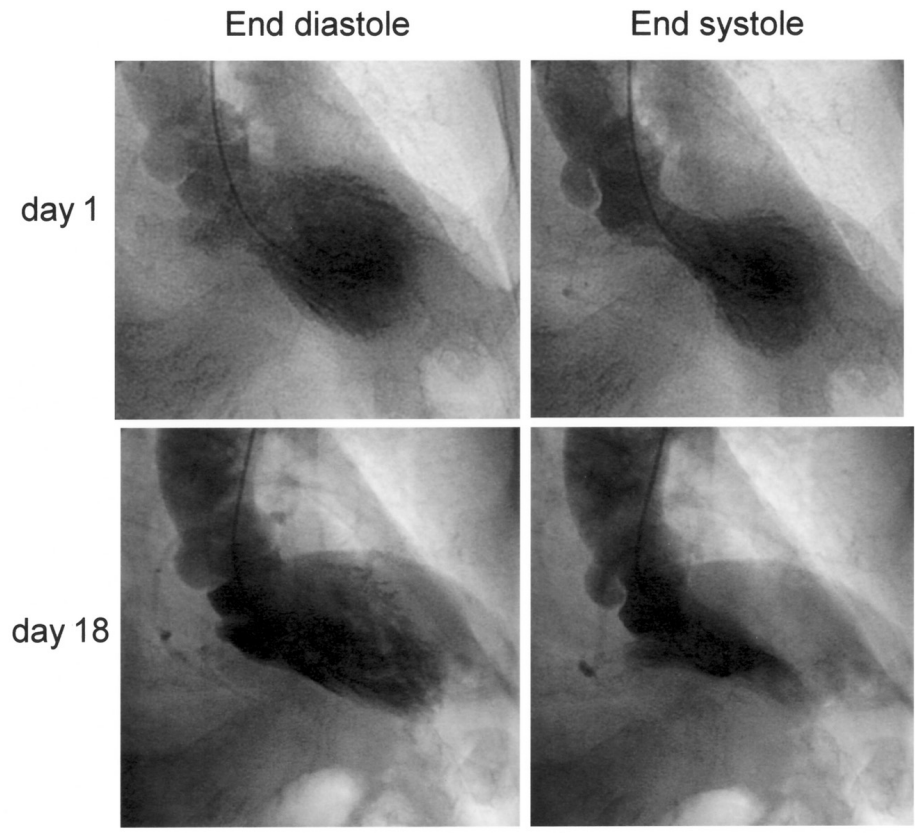

Figure 4. Left ventriculogram on day 1 and day 18 .

harmful due to her hyperosmolar state. At ten hours from admission, an electrocardiogram showed marked ST-segment elevation, following which electrical alternans appeared in leads V2 and 3 (Figure 2). At this time, serum Na was 172 $\mathrm{mEq} / \mathrm{L}$, plasma glucose $356 \mathrm{mg} / \mathrm{dL}$, and serum osmolality $386 \mathrm{mosmol} / \mathrm{L}$. We 


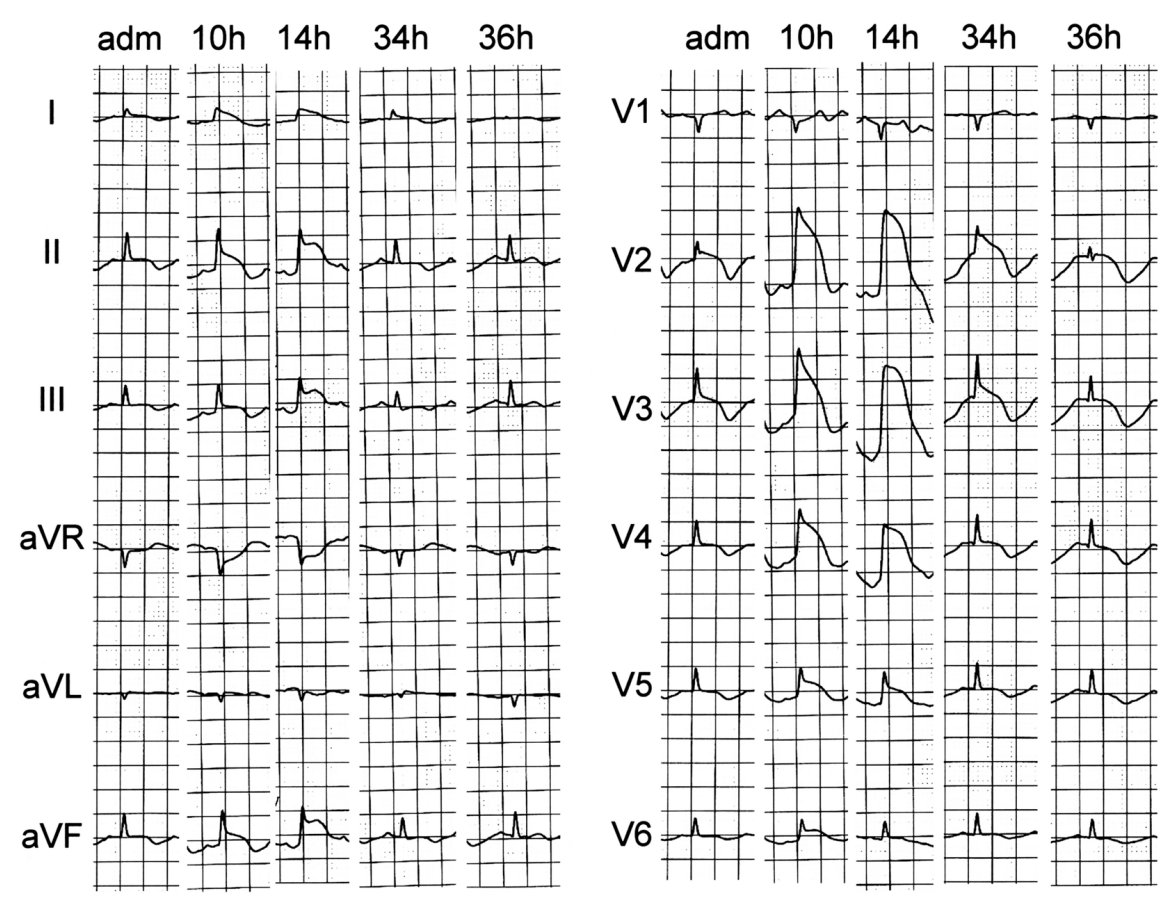

Figure 5. Serial changes in electrocardiogram. adm indicates on admission.

suspected acute myocardial infarction and emergent coronary angiography was performed. However, coronary angiography revealed no epicardial artery occlusion (Figure 3). Left ventriculography showed dyskinesis in the mid-ventricle and apex with preserved basal function indicating Takotsubo cardiomyopathy (Figure 4). Left ventricular pressure recordings showed no intraventricular pressure gradient. Marked ST-segment elevation persisted for about 24 hours. Thereafter, the ST-segment elevation gradually weakened and had completely disappeared at 36 hours from admission. A subsequent electrocardiogram showed $\mathrm{T}$ wave inversion but no abnormal Q waves (Figure 5). At this time, serum Na was $156 \mathrm{mEq} / \mathrm{L}$, plasma glucose $268 \mathrm{mg} / \mathrm{dL}$, and serum osmolality $346 \mathrm{mosmol} / \mathrm{L}$. Echocardiography revealed the left ventricular ejection fraction was $36 \%$ on the second day and $58 \%$ on the $10^{\text {th }}$ day. The peak value of creatine kinase MB was $89 \mathrm{IU} / \mathrm{L}$. On the third day, the serum concentration of adrenaline was $102 \mathrm{pg} / \mathrm{mL}$ (normal $<100$ ), noradrenaline $791 \mathrm{pg} / \mathrm{mL}$ (normal 100-450), and dopamine $189 \mathrm{pg} / \mathrm{mL}$ (normal $<20$ ). A left ventriculogram on the $18^{\text {th }}$ day from admission showed normal left ventricular function (Figure 4). 


\section{DISCUSSION}

Takotsubo cardiomyopathy is a novel cardiac syndrome characterized by transient left ventricular dysfunction with chest pain, electrocardiographic changes, and minimal myocardial enzymatic release mimicking acute myocardial infarction. ${ }^{4-6)}$ Exaggerated sympathetic stimulation may be the cause of this syndrome $^{4-6)}$ Takotsubo cardiomyopathy has been described in clinical states of catecholamine excess such as emotional stress, $^{4-6)}$ noncardiac surgery, ${ }^{4,5}$ subarachnoid hemorrhage, ${ }^{7)}$ and pheochromocytoma. ${ }^{8)}$

There have been several reports of cardiac complications with a hyperglycemic hyperosmolar state (HHS), such as acute myocardial infarction ${ }^{1,2)}$ and heart failure. ${ }^{3)}$ However, there have been no reports of Takotsubo cardiomyopathy with HHS.

The effects of hyperosmolarity on myocardium are myocardial dehydration and a consequent increase in intracellular calcium concentration, ${ }^{9,10)}$ inhibition of $\mathrm{Na}^{+}-\mathrm{K}^{+}$pump activity, ${ }^{11)}$ and intracellular alkalosis due to activation of the sarcolemmal $\mathrm{Na}^{+}-\mathrm{H}^{+}$exchanger. ${ }^{12)}$ On the other hand, the possible mechanism of Takotsubo cardiomyopathy is catecholamine-mediated myocardial stunning. Catecholamines induce myocardial injury through cyclic AMP-mediated calcium overload. ${ }^{13)}$ In addition, cathecholamines are a potential source of oxygenderived free radicals which interfere with sodium and calcium transporters and induce intracellular calcium overload. ${ }^{14)}$ Based on these findings, we propose that a hyperosmolarity-induced increase in intracellular calcium concentration may be the underlying mechanism of Takotsubo cardiomyopathy with HHS.

This case presented with marked ST-segment elevation and electrical alternans, which to the best of our knowledge are uncommon findings in Takotsubo cardiomyopathy. Electrical alternans seen on the ST segment was frequently observed in severe myocardial ischemia and is a predictor of life-threatening ventricular arrhythmia. ${ }^{15)} \mathrm{A}$ proposed mechanism of electrical alternans is delayed intracellular $\mathrm{Ca}^{2+}$ cycling mediated by sarcoplasmic reticulum and ryanodine receptors. ${ }^{16)}$ We believe that a hyperosmolarity-induced increase in intracellular calcium concentration may have overcome the delayed intracellular $\mathrm{Ca}^{2+}$ cycling in the myocardium and induced electrical alternans in this patient.

In HHS, ST-segment elevation on an electrocardiogram usually suggests acute myocardial infarction. However, our case indicates Takotsubo cardiomyopathy can occur in HHS. Further studies are necessary to clarify the relationship between Takotsubo cardiomyopathy and HHS.

Conclusion: We report a case of Takotsubo cardiomyopathy with marked STsegment elevation and electrical alternans complicated with HHS. This case indicates that cardiac complications in HHS include not only myocardial infarction but also Takotsubo cardiomyopathy. 


\section{REFERENCES}

1. Yildiz M, Güi C, Ozbay G. Hyperosmolar hyperglycaemic nonketotic coma associated with acute myocardial infarction: report of three cases. Acta Cardiol 2002; 57: 271-4.

2. Limas CJ, Samad A. Hyperosmolar nonketotic coma complicating acute myocardial infarction. Acta Cardiol 1971; 26: 105-13.

3. Braaten JT. Hyperosmolar nonketotic diabetic coma: diagnosis and management. Geriatrics 1987; 42: 83-8, 92.

4. Tsuchihashi K, Ueshima K, Uchida $\mathrm{T}$, et al. Transient left ventricular apical ballooning without coronary artery stenosis: a novel heart syndrome mimicking acute myocardial infarction. Angina Pectoris-Myocardial Infarction Investigations in Japan. J Am Coll Cardiol 2001; 38: 11-8.

5. Kurisu S, Sato H, Kawagoe T, et al. Tako-tsubo-like left ventricular dysfunction with ST-segment elevation: a novel cardiac syndrome mimicking acute myocardial infarction. Am Heart J 2002; 143: 448-55.

6. Wittstein IS, Thiemann DR, Lima JA, et al. Neurohumoral features of myocardial stunning due to sudden emotional stress. N Eng J Med 2005; 352: 539-48.

7. Kono T, Morita H, Kuroiwa T, Onaka H, Takatsuka H, Fujiwara A. Left ventricular wall motion abnormalities in patients with subarachnoid hemorrhage: neurologenic stunned myocardium. J Am Coll Cardiol 1994; 24: 636-40.

8. Yamanaka O, Yasumasa F, Nakamura T, et al. "Myocardial stunning" -like phenomenon during a crisis of pheochromocytoma. Jpn Circ J 1994; 58: 737-42.

9. Pogatsa G, Dubecz E. Effect of hyperglycaemia-induced hyperosmolality on heart function in the dog. Eur J Clin Invest 1979; 9: 147-50.

10. Bielefeld DR, Pace CS, Boshell BR. Hyperosmolarity and cardiac function in chronic diabetic rat heart. Am J Physiol 1983; 245: E568-74.

11. Whalley DW, Hool LC, Ten Eick RE, Rasmussen HH. Effect of osmotic swelling and shrinkage on $\mathrm{Na}(+)-\mathrm{K}+$ pump activity in mammalian cardiac myocytes. Am J Physiol 1993; 265: C1201-10.

12. Whalley DW, Hemsworth PD, Rasmussen HH. Sodium-hydrogen exchange in guinea-pig ventricular muscle during exposure to hyperosmolar solutions. J Physiol 1991; 444: 193-212.

13. Mann DL, Kent RL, Parsons B, Cooper G 4th. Adrenergic effects on the biology of the adult mammalian cardiocyte. Circulation 1992; 85: 790-804.

14. Bolli R, Marbán E. Molecular and cellular mechanisms of myocardial stunning. Physiol Rev 1999; 79: 609-34. (Review)

15. Rosenbaum DS, Jackson LE, Smith JM, Garan H, Ruskin JN, Cohen RJ. Electrical alternans and vulnerability to ventricular arrhythmias. N Engl J Med 1994; 330: 235-41.

16. Kameyama M, Hirayama Y, Saitoh H, Maruyama M, Atarashi H, Takano T. Possible contribution of the sarcoplasmic reticulum $\mathrm{Ca}(2+)$ pump function to electrical and mechanical alternans. J Electrocardiol 2003; 36: 125-35. 